\author{
SERIES 'AIRWAY MUCUS' \\ Edited by P.K. Jeffery \\ Number 1 in this Series
}

\title{
Airway mucosa: secretory cells, mucus and mucin genes
}

\author{
P.K. Jeffery, D. Li
}

\begin{abstract}
Airway mucosa: secretory cells, mucus and mucin genes. P.K. Jeffery, D. Li. @ERS Journals Ltd 1997.

ABSTRACT: The airway mucosa is lined by a continuous epithelium comprised of multiple cell phenotypes, several of which are secretory. Secretions produced by these cells mix with a variety of macromolecules, ions and water to form a respiratory tract fluid that protects the more distal airways and alveoli from injury and infection. The present article highlights the structure of the mucosa, particularly its secretory cells, gives a synopsis of the structure of mucus, and provides new information on the localization of mucin $(M U C)$ genes that determine the peptide sequence of the protein backbone of the glycoproteins, which are a major component of mucus.

Airway secretory cells comprise the mucous, serous, Clara and dense-core granulated cells of the surface epithelium, and the mucous and serous acinar cells of the submucosal glands. Several transitional phenotypes may be found, especially during irritation or disease. Respiratory tract mucins constitute a heterogeneous group of high molecular weight, polydisperse richly glycosylated molecules: both secreted and membrane-associated forms of mucin are found.

Several mucin $(M U C)$ genes encoding the protein core of mucin have been identified. We demonstrate the localization of $M U C$ gene expression to a number of distinct cell types and their upregulation both in response to experimentally administered lipopolysaccharide and cystic fibrosis.

Eur Respir J 1997; 10: 1655-1662.
\end{abstract}

Dept of Histopathology, Lung Pathology Unit, National Heart and Lung Institute, Imperial College, London, UK.

Correspondence: P.K. Jeffery

Lung Pathology Unit

Histopathology

Royal Brompton Hospital

Sydney Street

London

SW3 6NP

UK

Keywords: Airway mucosa

lung

mucin

mucus

secretory cells

Received: February 241997

Accepted for publication February 261997
The epithelium lining the airways of the normal mammalian lung consists of many morphologically distinct cell types with different, but sometimes overlapping, functions. In disease, the integrity of the epithelium may be compromised, such as in symptomatic asthma [1]. In bronchitis, there are increased numbers of surface mucussecreting cells and enlargement of submucosal glands in bronchi, and mucous metaplasia in bronchioles [2]. In cystic fibrosis, altered movement of ions and macromolecules through and between cells can lead to defective transepithelial flux of water and drying of airway secretions [3].

The airway wall comprises epithelial, lymphoid, muscular, vascular and nervous elements interspersed in a pliable connective tissue support, arranged as: 1) a lining mucosa of surface epithelium supported by a reticular basement membrane and a poorly-defined elastic lamina propria (or subepithelium), in which there are bronchial blood vessels, nerve bundles and free cells (including fibroblasts and mononuclear cells); 2) a submucosa, in which lie the bulk of the mucus-secreting glands, muscle and cartilage plates; and 3) a relatively thin adventitial coat.

\section{Surface epithelium and secretory cells}

The airway epithelium includes the surface epithelium, which lines all airways (nose to alveolus) and which is continuous with that forming the tubulo-acinar sub- mucosal mucus-secreting glands, which develop from the surface $[4,5]$. The stratified squamous epithelium lining of much of the larynx gives way to one which is pseudostratified, ciliated and columnar when the trachea is reached. Where it is "pseudostratified", all cells rest on the basement membrane, but not all reach the airway lumen (fig. 1). In humans, this type of epithelium persists throughout the major bronchi, becoming simple cuboidal towards the periphery. Ciliated cells

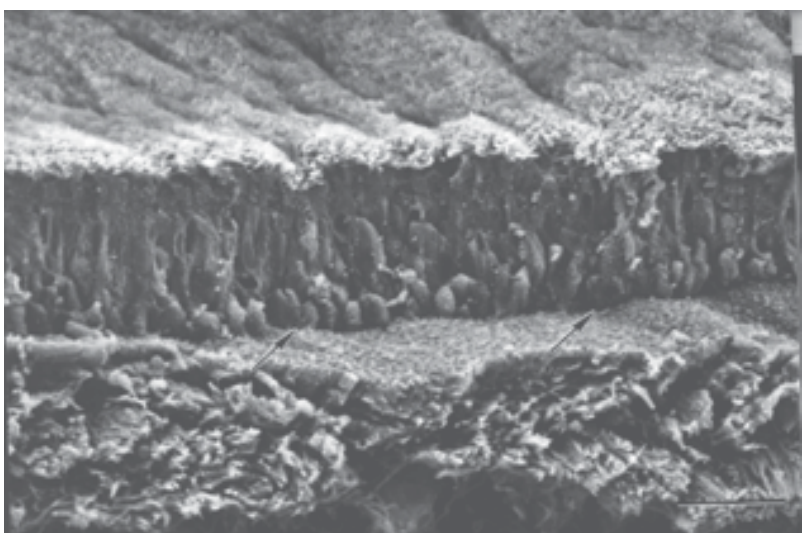

Fig. 1. - Scanning electron micrograph (SEM) demonstrating the pseudostratified bronchial epithelium with "fields" of cilia on the luminal surface and the region of contact with its basement membrane (arrows). All illustrations are of human airways. (Internal scale bar=40 $\mu \mathrm{m})$. 


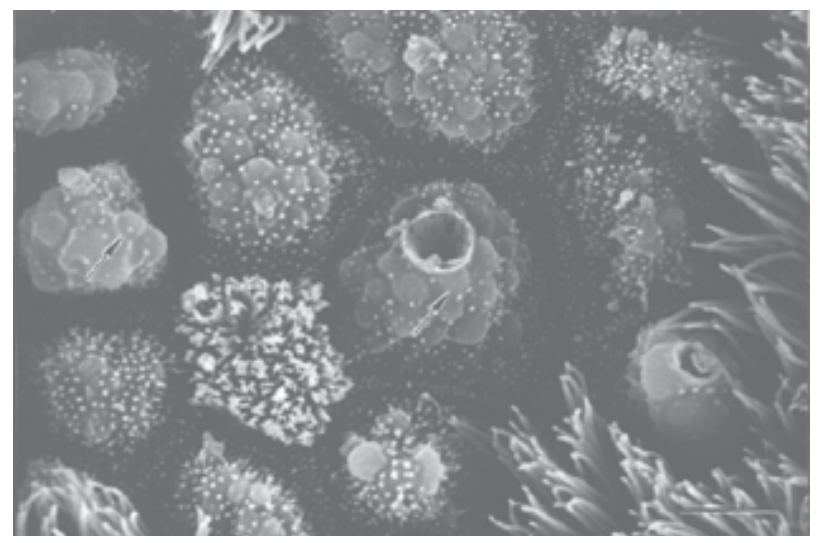

Fig. 2. - Scanning electron micrograph (SEM) of the luminal surface showing the apices of ciliated and goblet cells: the intracellular secretory granules of the latter can be seen beneath the plasma membrane (arrows). (Internal scale bar $=30 \mu \mathrm{m}$ ).

predominate, interspersed with mucus-secreting (goblet) cells, which are regularly found in the tracheobronchial tree (fig. 2) but rarely in bronchioles of less than $1 \mathrm{~mm}$ diameter [6].

A variety of cell types is recognized in airway surface epithelium: at least eight different epithelial cell types have now been delineated, depending on species $[7,8]$. In addition, cells involved in the immune response and its reactions may migrate through the epithelial reticular basement membrane: some of these remain within the surface epithelium, whereas others are in the process of passing through to the luminal surface [9]. The terminal processes of sensory nerve fibres, whose cell bodies lie deep beneath the epithelium, pierce the epithelial basement membrane and lie surrounded by epithelial cells, where they initiate airway reflexes, such as bronchoconstriction and cough [10]. These endings may be inappropriately stimulated in conditions such as asthma and chronic bronchitis. Secretions produced by airway epithelial cells mix with a variety of macromolecules, ions and water, whose passage from vascular compartment to airway lumen is largely controlled by the epithelium itself (this will be the subject of a forthcoming article in this series, by J. Widdicombe). Thus, respiratory tract fluid comprises a mixture of mucous-glycoproteins, glycosaminoglycans, proteins/peptides, lipids, antiproteases/ antioxidants, ions and water, whose origin is both from epithelial and vascular sources. The secretory cells will now be considered in more detail.

\section{Mucous cell}

In human trachea, the normal mean density of surface mucous cells (fig. 2) is estimated at 6,000-7,000 cells $\cdot \mathrm{mm}^{-2}$ surface epithelium [11]. By electron microscopy, the mucous cell has electron-dense cytoplasm containing electron-lucent, confluent granules of about $800 \mathrm{~nm}$ diameter (fig. 3). Most contain high molecular weight glycoprotein, which is acidic due to sialic acid or sulphate groups located at the ends of the oligosaccharide side-chains, which branch from a backbone of protein [12]. Secretion of the correct amount of mucus with an optimum viscoelastic profile is important in the maintenance of normal mucociliary clearance [13]. Alterations in the predominant histochemical type of mucus have been associated with airway irritation, carcinogenesis, chronic bronchitis and cystic fibrosis (see below), but no novel glycoprotein moiety has been identified. The numbers of mucus-secreting cells increase in chronic bronchitis and, experimentally, in animal models of bronchitis, following inhalation of sulphur dioxide [14], tobacco smoke $[15,16]$, or intratracheal instillation of endotoxin (lipopolysaccharide (LPS)) [17, 18]. Their increase in number and extension to the peripheral bronchioles is one characteristic of small airways disease [19]. The mucous cell is clearly capable of division and may show stem cell multipotentiality [20].

The solubility and viscosity of mucus varies considerably with ionic strength, and divalent cations, such as calcium, cause mucus to form a rigid cross-linked gel, which may be difficult to clear by mucociliary action or cough. In cystic fibrosis (CF), high calcium and sulphate content is reported in tracheobronchial secretions [21]. In biopsy studies, mucous cells from patients with $\mathrm{CF}$ have been shown to contain significantly raised intracellular calcium and sulphate levels and lower potassium levels than those of patients with chronic bronchitis [22]. The clinical significance of these results is as yet unclear. In asthma, there is controversy as to the extent of goblet cell hyperplasia in bronchi and metaplasia in bronchioles. The blockage of airways by highly tenacious plugs in fatal asthma appears to be the result of a mixture of inflammatory exudate, fibrin and epithelial-derived mucins.

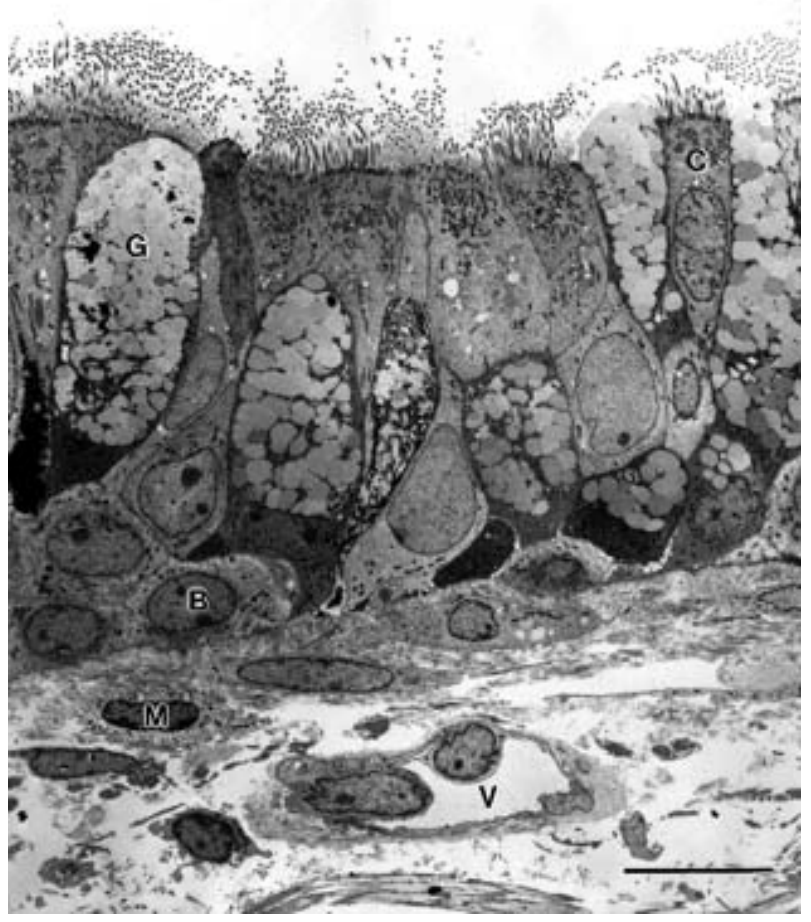

Fig. 3. - Transmission electron micrograph (TEM) showing through the surface epithelium and the underlying lamina propria. The epithelium comprises goblet $(\mathrm{G})$, ciliated $(\mathrm{C})$ and basal $(\mathrm{B})$ cell types. A bronchial vessel (V) and mast cell (M) are labelled. The goblet cell has electron-lucent granules. (Internal scale bar $=10 \mu \mathrm{m}$ ). 


\section{Serous cell}

Serous cells have electron-dense cytoplasm, much rough endoplasmic reticulum and, in contrast to mucous cells, discrete electron-dense granules of about $600 \mathrm{~nm}$ diameter (fig. 4). Morphologically, serous cells of the surface epithelium resemble those present in the submucosal glands. They have been described in surface epithelium only in the rat, cat, young hamster and human foetus [23]. They have also been described in human small bronchi and bronchioles [24]. Many contain neutral mucin, and there is evidence that some may also contain a nonmucoid substance, probably lipid [25].

\section{Clara (nonciliated bronchiolar) cell}

Clara cells in humans are restricted in location to the terminal bronchiolus, where they typically bulge into the airway lumen and contain electron-dense granules of about 500-600 $\mathrm{nm}$ diameter, ovoid in humans but irregular in most other species [26] (fig. 5). The function(s) of this cell type is as yet unclear. It has the capacity to metabolize xenobiotics, may produce a carbohydrate (hypophase) component of surfactant [27], or an antiprotease [28, 29], and is known to have ion-absorbing and secreting properties [30]. Furthermore, the Clara cell

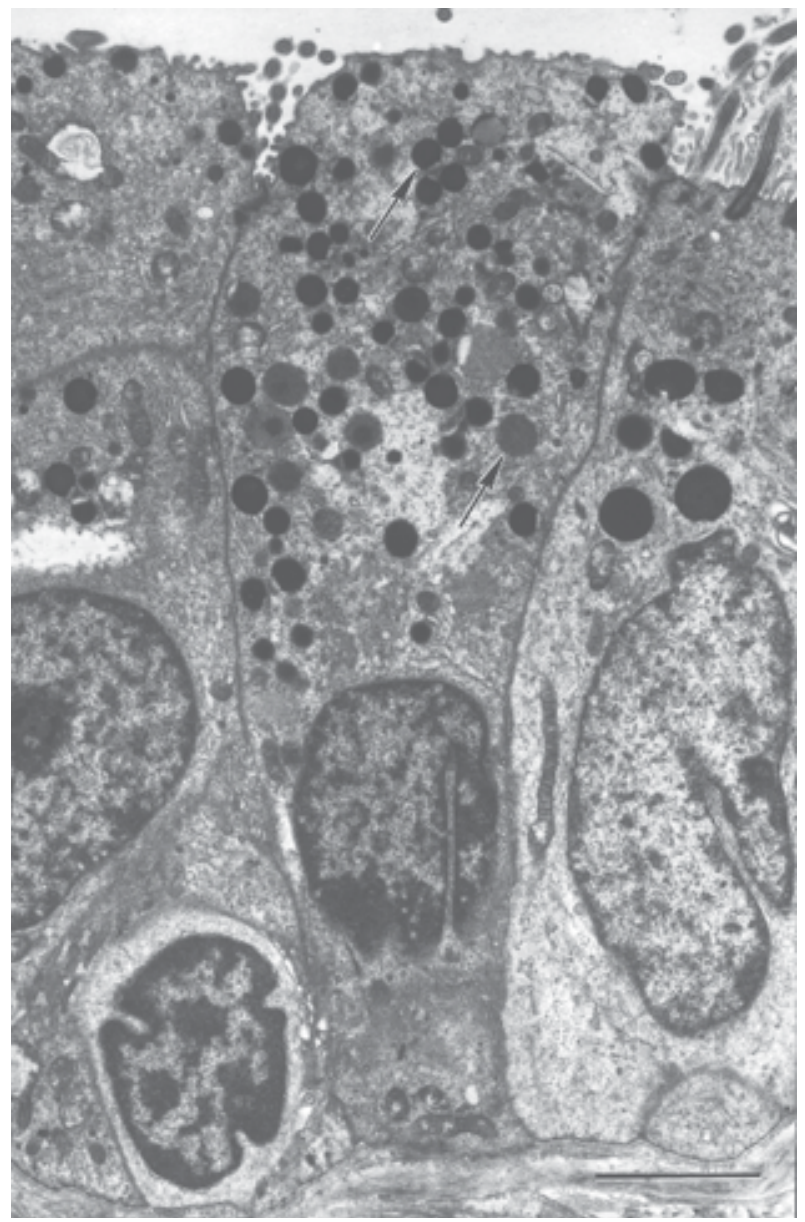

Fig. 4. - Transmission electron micrograph (TEM) of a serous cell containing secretory granules of varying electron-density (arrows). (Internal scale bar $=1.5 \mu \mathrm{m}$ ).

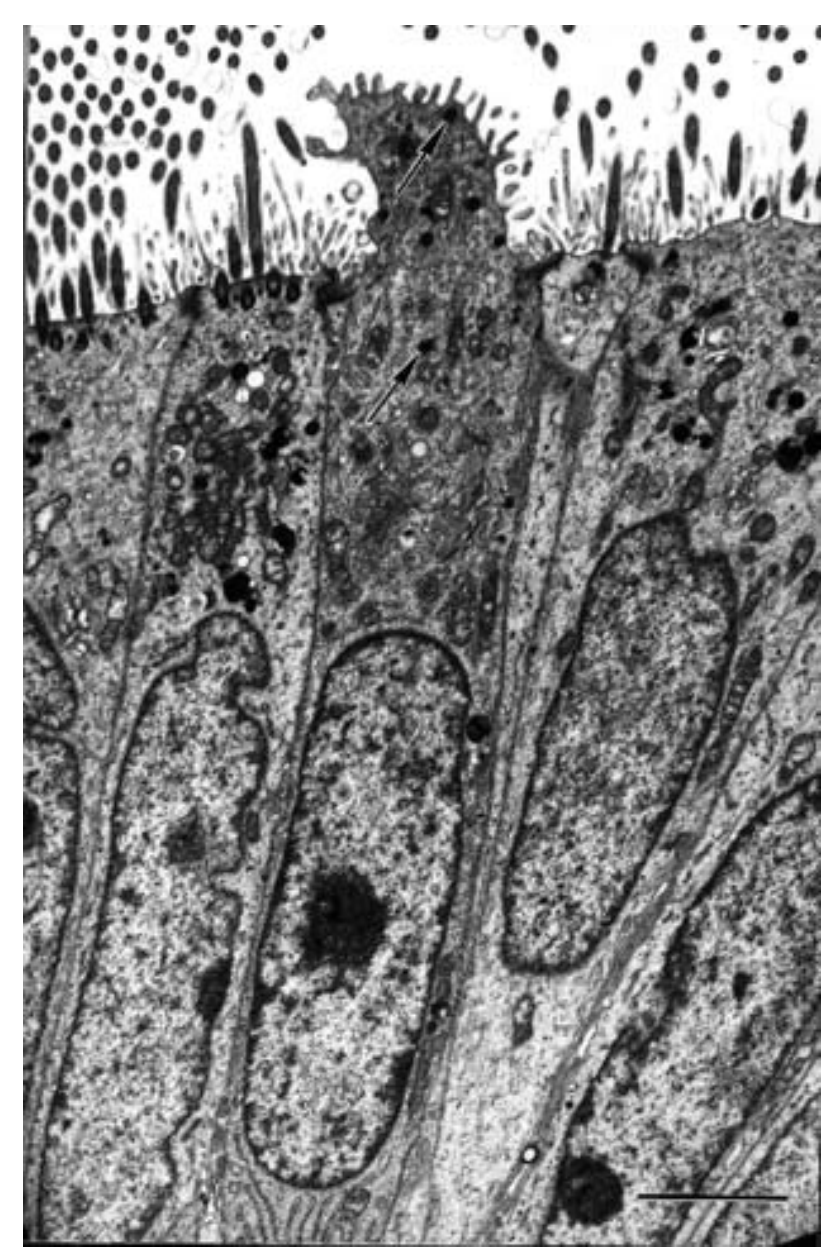

Fig. 5. - Transmission electron micrograph (TEM) of a nonciliated bronchiolar (Clara) cell containing a few, small electron-dense granules (arrows). The apex of the cell protrudes into the airway lumen. (Internal scale bar=2.0 $\mu \mathrm{m}$ ).

acts as the stem cell of small airways, where basal and mucous cells are normally sparse: both ciliated and mucous cells may develop from the Clara cell subsequent to its division and differentiation [20].

Dense-core granulated (DCG) cell (synonyms: endocrine, Kultchitsky and Feyrter cell)

Argentaffin-positive and argyrophilic cells have been identified within the surface epithelium by light microscopy. By electron microscopy, DCG cells are infrequently found, generally basal in position, but often with a thin cytoplasmic projection reaching the airway lumen $[19,31]$. Single cells and clusters of such cells may also be associated with nerve fibres (i.e. so-called neuroepithelial bodies or neurite-receptor complexes) [19, 32]. The cytoplasm of DCG cells usually contains large numbers of small (70-150 nm) spherical granules, each with an electron-dense core surrounded by an electron-lucent halo (fig. 6). Granule subtypes have been described and the cells may contain biogenic amines [33] or peptides, such as bombesin [34], which, when released, may influence vascular and bronchial smooth muscle tone, mucous secretion and ciliary activity. The location of the cell 


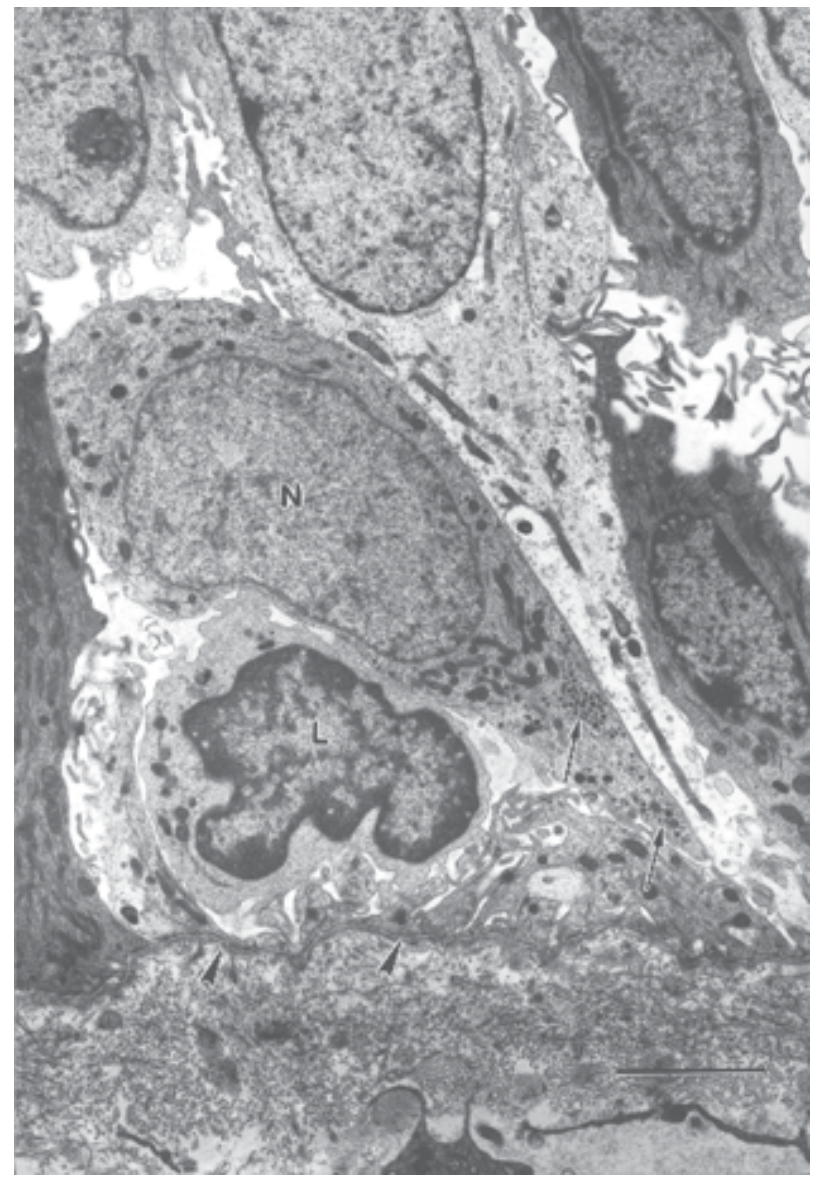

Fig. 6. - Transmission electron micrograph (TEM) of a neuroendocrine cell $(\mathrm{N})$ at the base of the surface epithelium, whose cytoplasm contains small electron-dense-cored granules (arrows). There is an adjacent intraepithelial lymphocyte (L) above the basement membrane (arrow heads). (Internal scale bar=3.0 $\mu \mathrm{m}$ ).

in surface epithelium and its cytoplasmic content make it a prime candidate for sensing hypoxia in the airway lumen: as a consequence, vasoactive substances may be released, which cause local vasoconstriction and shunting of blood to better ventilated zones of the lung.

\section{Transitional cells}

Abnormal epithelium may include a number of cells, each of which shows features transitional to two or more morphologically well-defined cell types [19], for example:

Serous-mucous cells may be found rarely in normal specific-pathogen free (SPF) rats, but are frequent in rats made "bronchitic" by inhalation of cigarette smoke. They may also be found in areas of grossly normal human epithelium in lungs resected for carcinoma. The cells contain secretory granules of the mucous type, with electron-dense cores resembling serous granules.

Clara-mucous cells may be found, experimentally, after irritation by sulphur dioxide [19], or multiple injections of the beta-adrenergic agonist, isoprenaline sulphate. The transitional cell retains the protruding apex, abundance of smooth endoplasmic reticulum and many of the electron-dense granules of the Clara cell but, in addition, has many large mucous granules.

DCG-mucous cell transitional forms have been found by histochemistry in the gut and by electron microscopy both in gut and bronchi [19].

Basal-mucous-squamous cell tracheobronchial epidermoid metaplasia is a change from an epithelium which is pseudostratified, mucus-secreting and ciliated to one which is stratified and keratinized. MCDoweLL and TRUMP [35] have presented evidence and argued convincingly that such an epidermoid change arises subsequent to division of mucous cells, rather than arising directly from existing basal cells. Experimentally, carcinogens, mechanical trauma and vitamin A deficiency may each induce changes in mucous cells, leading to squamous cell metaplasia with or without stratification and keratinization [36].

Ciliated-secretory cells have been identified after injections of isoprenaline sulphate or exposure to LPS in rats, and, occasionally, in resected human lung [19] (fig. 7). The cell retains the electron-lucent cytoplasm of the ciliated cell with apical microvilli and ciliary basal bodies, but cilia are absent and there are secretory granules in the cytoplasm. The long slender microvilli, which normally project between cilia of ciliated

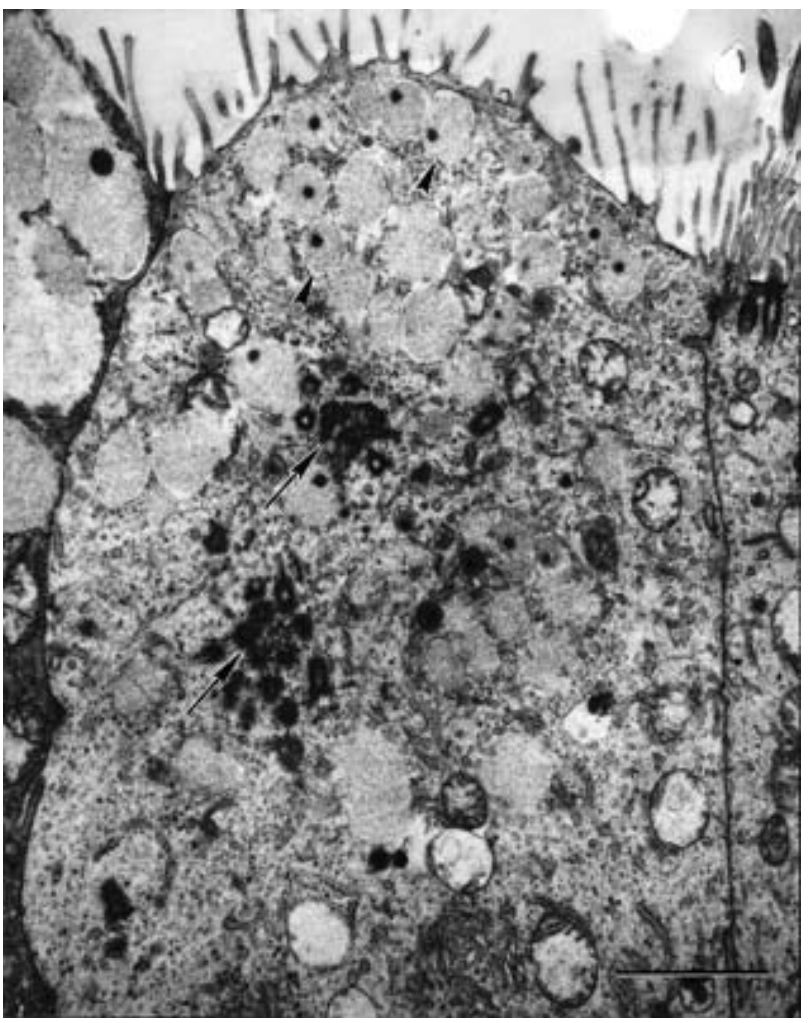

Fig. 7. - Transmission electron micrograph (TEM) of a transitional cell in bronchial epithelium, showing features both of ciliated and mucous secretory cells: basal bodies (arrows) and mucous granules (arrow heads), respectively. Elongated surface microvilli and electron-lucent cytoplasm are also characteristics of the ciliated cell. (Internal scale bar=2.0 $\mu \mathrm{m}$ ). 
cells, are associated with an acidic surface mucosubstance, probably a glycosaminoglycan, which may be an important component of mucosubstance [25, 37-39]. The microvillus border and associated pinocytotic vesicles may play a role in ion translocation and fluid absorption, and thereby control the depth of the periciliary fluid layer in which the cilia beat. The extent to which this cell surface mucosubstance may be released and contribute to respiratory tract fluid is presently unclear.

\section{Submucosal glands}

The submucosal glands in humans are relatively numerous and in the lower respiratory tract are found wherever there is supportive cartilage in the airway wall, i.e. from larynx to small bronchi. The volume, distribution and histochemical composition of gland cells shows considerable species variation $[7,40]$. It has been estimated that some 4,000 glands are present in the human trachea [41]. Developing from surface epithelium in utero, each gland unit is of the tubulo-alveolar type, and in humans may be composed of four regions whose lumina are continuous: 1) a relatively narrow ciliated duct in continuity with the surface epithelium; 2) an expanded collecting duct of cells of indeterminate morphology or of eosinophilic cells (also referred to as "oncocytes") packed with mitochondria; 3) mucous tubules and mucous acini; and 4) serous acini [42]. The movement of ions and water from the vascular compartment to the airway lumen is regulated both by surface epithelium and submucosal glands [43]. In the latter, it is suggested that watery, serous secretions pass from the outermost regions of each gland into the mucous tubules and mix, and that the ionic balance of the mixed secretion may be adjusted in the collecting duct before its discharge through the ciliated duct to the bronchial lumen. Discharge is aided by contractile myoepithelial cells, which form a basket-like structure around the outer aspects of the acinus.

Both synthesis of the intracellular section and discharge are influenced by nerves, whose terminals lie adjacent to (in humans) or pierce (as in the cat) the secretory unit [10]. There is evidence that both parasympathetic and sympathetic agonists stimulate secretion, although the quantity and quality of the resulting secretion may differ with each [44]. Submucosal glands form a major source of tracheobronchial mucus, with the balance contributed to by surface epithelium, and the ratio dependent upon the nature of the stimulus. Submucosal gland mass increases in chronic bronchitis, asthma and cystic fibrosis; the increase is probably due to cell proliferation within each secretory acinus rather than to an increase in the number of gland units per se [45].

\section{Mucous-glycoprotein}

Mucins constitute a heterogeneous group of high molecular weight, polydisperse, richly glycosylated molecules. There are secretory and membrane-associated forms of mucin. Secretory mucins contribute to the viscid mucus of the tracheobronchial, gastrointestinal and reproductive tracts, and typically form extremely large oligomers through linkage of their protein monomers by disulphide bonds. These proteins are secreted from the cell and form the mucous gel, which becomes an integral part of the mucociliary escalator. In contrast, the membrane-associated mucins have a hydrophobic membrane-spanning domain and have not been observed to form oligomer complexes. Mucins contain almost $80 \%$ sugars by weight and a very characteristic amino acid composition, with a high content of threonine and serine in their backbone. The mucin polypeptide backbone has been difficult to sequence by conventional procedures due to the presence of numerous heterogeneous $\mathrm{O}$-linked glycan chains.

The normal histochemical profile of cellular glycoprotein varies with airway level, stage of maturation and species. In humans, the mucus-secreting cells of the airways may produce either neutral, acidic glycoproteins or a mixture of these, the acidity due to sialic acid and/ or sulphate esters [46-48]. The majority of surface secretory cells contain a glycoprotein consisting of a protein backbone with sugar side-chains, having terminal sialic acid, penultimate galactose residues and a variable content of sulphate esters. The high iron diamine-alcian blue procedure demonstrates mainly sulphomucin in surface epithelium. The ratio of radioactive sulphate to glucosamine uptake is higher in surface than submucosal gland mucous cells, and several studies have indicated a highly sulphated acidic secretion from the surface $[49,50]$, particularly in cultured epithelial cells from patients with cystic fibrosis [51].

The cells of mucous and some serous acini of the submucosal glands both contain a glycoprotein with sulphate esters. Serous acini differ from mucous acini in producing a secretion with less carbohydrate, little or no sialic acid, and no terminal or penultimate galactose [49]. There is evidence from several studies that serous cells may normally produce the secretory component of immunoglobulin A (IgA), lysozyme, lactoferrin, albuminlike molecules and glycosaminoglycans [52-55]. Alterations in the predominant histochemical type of glycoprotein have been shown in disease and following experimental irritation. In "fatal" bronchitis, there is a reduction in the proportion of sialomucin susceptible to digestion by the enzyme sialidase, an increase in sialomucin resistant to such digestion, and an increase in sulphomucin [56, 57]. After experimental irritation by sulphur dioxide or tobacco smoke, there is a shift from sialomucin to sulphomucin $[14,48]$; a similar shift is seen in human smokers [58].

\section{Mucin genes}

With the development of molecular biological techniques, the complementary deoxyribonucleic acid (cDNA) sequences of mucin genes can now be obtained and the amino acid sequences of the mucin peptide core deduced. At the present time, there are at least eight human mucin genes (MUC1 to MUC4, MUC5AC, MUC5B, $M U C 6$ and $M U C 7)$, one mouse mucin gene (MUC1), one hamster mucin gene ( $M U C 1)$, three rat mucin genes $R A M 7 S, M U C 2$ mucin gene and a $M U C 2$ homologue, and $R M U C 176$. Several other mammalian mucin genes from bovine submaxillary gland, canine tracheobronchial and porcine submaxillary gland have also been discovered. These discoveries have accelerated and intensified research into the extent of mucin gene expression in distinct airway conditions, and yet the specific role of mucin genes is at present unclear. 


\section{Mucin gene expression in experimental animals}

The specific mechanisms by which pathogens (and their derivatives) and irritants induce upregulation of mucin genes are unknown: they probably act either by increasing the transcription rate or decreasing the rate of degradation of mucin messenger ribonucleic acid (mRNA). The isolation of a number of "mucin" genes has added a new dimension to the use of animal models to investigate the pathogenesis of hypersecretory disease.

JANY et al. [59] observed human MUC2 gene expression in $\mathrm{SO}_{2}$-exposed rats. These authors used rats exposed to $400 \mathrm{ppm} \mathrm{SO}_{2}$ for $3 \mathrm{~h} \cdot$ day $^{-1}, 5$ days a week, for $1-3$ weeks, and found the airways contained increased numbers of goblet cells and visible mucinous secretions in the airway lumen. In parallel, they applied Northern blot analysis, using the total ribonucleic acid (RNA) extracted from the rat lung and hybridized it with human $M U C 2$ cDNA (SMUC41) and demonstrated upregulation of the MUC2 gene in the $\mathrm{SO}_{2}$-exposed rats: superadded Sendai virus infection intensified mucin gene expression. These results suggested that pathogen- and irritant-induced goblet cell hyperplasia and hypersecretion may be controlled, in part, at the level of mucin mRNA.

In our experience of an endotoxin-induced rat airway model of goblet cell hyperplasia (submitted for publication), we found that expression of the gene "rat airway mucus" (RAM7S) was increased four- to sixfold at 24$48 \mathrm{~h}$ after intratracheal instillation of endotoxin (LPS), and the increased level lasted for 16 days post-LPS. The first $24 \mathrm{~h}$ after LPS instillation was characterized by an increase of intracellular mucin, but increased (RAM7S) gene expression was delayed. After $48 \mathrm{~h}$, intracellular mucin and mRNA were both increased. We speculated that: 1) mucin discharge and synthesis within $24 \mathrm{~h}$ postLPS treatment does not require mucin gene expression, but relies upon an alteration of secretory cell phenotype (i.e. a metaplastic phase) due, in part, to an increase of cell (i.e. plasma membrane) permeability, pinocytosis, and swelling of the cell and its granules; 2) at $48 \mathrm{~h}$ postLPS, goblet cells express mucin gene and also enter a phase of proliferation; 3) When the irritant is removed, goblet cells are likely to reduce their mucin gene expression and their proliferative phase. The recovery phase is relatively slow, and may last several weeks in animals and several months or years in humans.

\section{Localization of mucin genes in human airways}

Little research has been performed with regard to localization of mucin genes in human airways by in situ hybridization. There are three previously published full reports of the localization of $M U C 2$ gene expression in human airway tissues. In the study published by AUDIE et al. [60], bronchial mucosae were obtained from four patients, whose lungs had been surgically resected for cancer. A radiolabelled antisense oligonucleotide probe corresponding to the tandem repeat domain of $M U C 2$ was applied, and localized to occasional goblet cells of the surface epithelium and to submucosal gland ducts, but not to their secretory acini. In contrast, oligonucleotide probes to $M U C 4, M U C 5 B$ and $M U C 5 C$ strongly labelled the gland acinar cells indicating that several distinct mucin genes are expressed in the mucosa either by the same or distinct cells of the epithelium and glands. CHAMBERs et al. [61] reported the relative expression and localization of $M U C 2$ and $M U C 1$ in human foetuses, three neonates and an unspecified number of "normal" lung tissues from surgical resections for carcinoma in adults. The radiolabelled antisense probe, pHAM1 (a 92 base pair (bp) portion of the $M U C 2$ tandem repeat) was reported to hybridize to goblet cells in the epithelium both of adult main bronchus and bronchioles, and was restricted to the surface epithelium of large airways after 19 weeks of gestation. In contrast, MUC1 gene expression was detected by 12.5 weeks of gestation and was more peripherally distributed. DOHRMAN et al. [62] compared the localization of $M U C 2, M U C 3$ and lysozyme mRNA transcripts in three surgical specimens of human bronchi from lungs resected for carcinoma. The HAMI antisense radiolabelled probe localized heavily to cells in the bronchial surface epithelium thought to represent $20-30 \%$ of the goblet cell phenotype. These authors also reported that $M U C 2$ gene was weakly and diffusely expressed in submucosal gland acini both of the serous and mucous phenotype. In contrast, the lysozyme antisense probe used, showed strong labelling of serous gland acini.

Our own findings [63] in the nasal mucosa demonstrate that $M U C 2$ mRNA transcripts are present in: 1) serous and mucous acini of submucosal glands; 2) ciliated and basal cells of the surface epithelium; and 3) occasionally, mononuclear inflammatory cells (fig. 8a
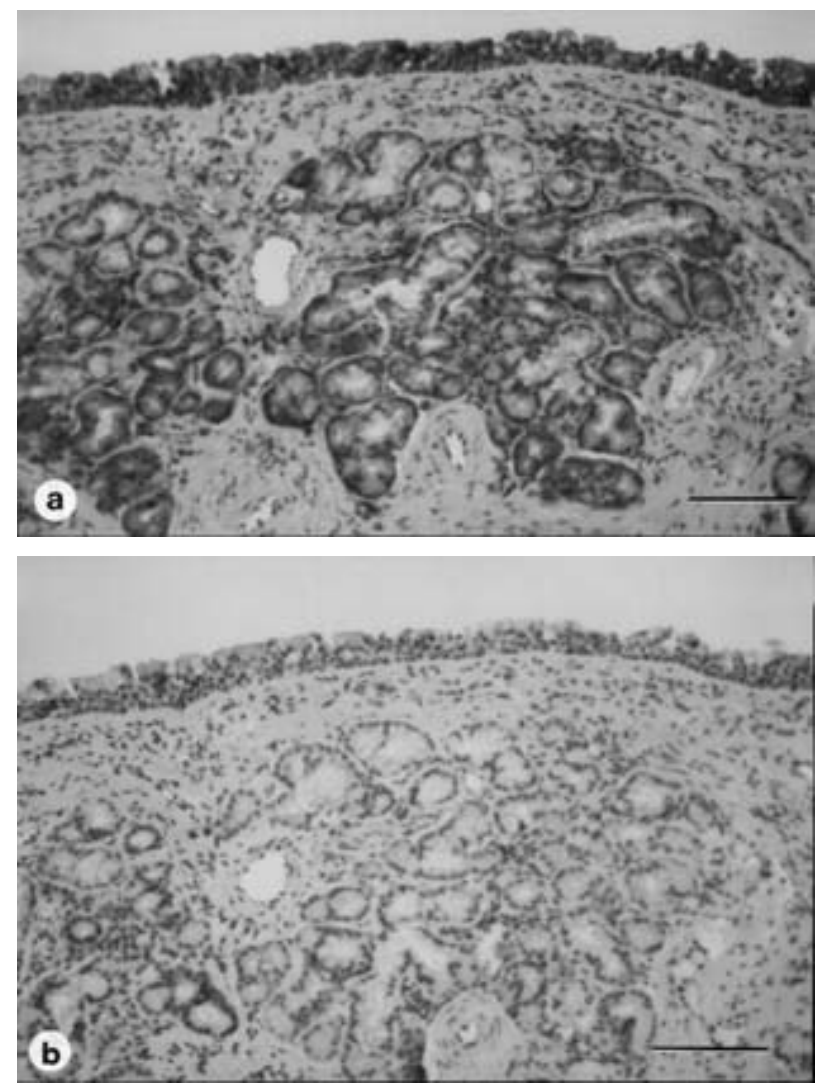

Fig. 8. - Light micrographs showing gene expression for $M U C 2$ in human nasal mucosa from a patient with cystic fibrosis. a) MUC2 messenger ribonucleic acid (mRNA) transcripts are highly expressed in the mucus-secreting glands and surface epithelium; b) the sense probe shows no localization. (Internal scale bar $=230 \mu \mathrm{m}$ ). 
and $b$ ). The percentages (mean \pm SEM) of serous and mucous acini showing positivity for $M U C 2$ gene expression in four samples surgically resected from non-CF subjects were: $25 \pm 6 \%$ and $27 \pm 3 \%$, respectively. Compared with the non-CF subjects, the mean percentage of acini showing $M U C 2$ gene expression in the four placebo-treated $\mathrm{CF}$ subjects was significantly higher for serous acini $(80 \pm 13 \%$; $p<0.05$, t-test), but not for mucous acini $(53 \pm$ $17 \%$; $\mathrm{p}=0.38$ ). In $\mathrm{CF}$ and non-CF groups, where present, MUC2 positivity was strongly expressed and constituted approximately $84 \%$ of the cell area in serous acini, whereas it was less obvious and confined to the perinuclear area of cells in mucous acini. A significantly greater proportion of the surface epithelium was positive for $M U C 2$ mRNA transcripts in the $\mathrm{CF}$ subjects $(89 \pm 1 \%)$ than in the surgically resected tissues of the four non-CF subjects $(19 \pm 4 \%)(p=0.02)$. These novel findings in the nasal mucosa are in the process of being extended to studies of bronchial biopsies obtained from subjects with asthma and chronic bronchitis.

\section{Summary}

The airway epithelium is comprised of many interacting structural components and inflammatory cells. Several morphologically distinct secretory cell types are present in the surface epithelium and submucosal glands. The secretions produced are, in part, high molecular weight, richly glycosylated, complex molecules, whose protein backbone consists of variable numbers of amino acids encoded by several "mucin" genes. The relative proportions of epithelial cell phenotypes and their secretory component alters in disease, and this may involve a metaplastic change where the characteristics of several morphological phenotypes may be found in one cell. In concert with this, there is altered expression of mucin genes and those which encode the enzymes responsible for mucin glycosylation. In airway disease, there may be mucosal damage, altered viscoelasticity of secretions and failure of clearance, with the enhanced likelihood of bacterial colonization leading to epithelial destruction. Further research in this area is required to improve our understanding of the function of mucin genes and of both the beneficial and potentially harmful effects of mucous hypersecretion.

\section{References}

1. Jeffery PK, Wardlaw A, Nelson FC, Collins JV, Kay AB. Bronchial biopsies in asthma: an ultrastructural quantitative study and correlation with hyperreactivity. Am Rev Respir Dis 1989; 140: 1745-1753.

2. Jeffery PK. Tobacco smoke-induced lung disease. In: Cohen RD, Lewis B, Alberti KGMM, Denman AM, eds. The Metabolic and Molecular Basis of Acquired Disease. London, Baillière Tindall, 1990; pp. 466-495.

3. Jeffery PK. Form and function of mammalian airway epithelium. In: Jones CJ, ed. Advances in Cell Physiology and Cell Culture. Lancaster, Kluwer Acad Pub, 1990; pp. 195-220.

4. Jeffery PK. Embryology and growth of the normal lung. In: Brewis RAL, Gibson GJ, Geddes DM, eds. Respiratory Medicine. Toronto, Baillière Tindall, 1990; pp. 3-20.

5. Cutz E. Cytomorphology and differentiation of airway epithelium in developing human lung. In: McDowell
EM, ed. Lung Carcinomas. London, Churchill-Livingstone, 1987; pp. 1-41.

6. Lumsden AB, McLean A, Lamb D. Goblet and Clara cells of human distal airways: evidence for smoking-induced changes in numbers. Thorax 1984; 39: 844-853.

7. Jeffery PK. Morphology of airway surface epithelial cells and glands. Am Rev Respir Dis 1983; 128: S14-S20.

8. Plopper CG, St.George J, Pinkerton KE, et al. Tracheobronchial epithelium in vivo: composition, differentiation and response to hormones. In: Thomassen DG, Netteshiem P, eds. Respiratory Epithelium. New York, Hemisphere Pub., 1990; pp. 6-23.

9. Jeffery PK, Corrin B. Structural analysis of the respiratory tract. In: Bienenstock J, ed. Immunology of the Lung. New York, McGraw-Hill, 1984; pp. 1-27.

10. Jeffery PK. Innervation of the airway mucosa: structure, function and changes in airway disease. In: Goldie R, ed. Immunopharmacology of Epithelial Barriers. Vol 8. The Handbook of Immunopharmacology (C. Page, series ed.). London, Academic Press, 1994; pp. 85-118.

11. Ellefsen P, Tos M. Goblet cells in the human trachea: quantitative studies of a pathological biopsy material. Arch Otolaryngol 1972; 95: 547-555.

12. Carlstedt I, Sheehan JK. Macromolecular properties and polymeric structure of mucus glycoproteins. In: Nugent J, O'Connor M, eds. Mucus and Mucosa, Ciba Foundation Symposium 109. Bath, Pitman, 1984; pp. 157-172.

13. Puchelle E, Zahm JM, Petit A. Spinability and transport properties of sputum in chronic bronchitis. In: Chantler N, Elder JB, Epstein M, eds. Mucus in Health and Disease. New York, Plenum Press, 1982; pp. 397-398.

14. Lamb D, Reid L. Mitotic rates, goblet cell increase and histochemical changes in mucus in rat bronchial epithelium during exposure to $\mathrm{SO}_{2}$. J Pathol Bacteriol 1968; 96: 97-111.

15. Jeffery PK, Reid L. The effect of tobacco smoke with or without phenylmethyloxadiazole (PMO) on rat bronchial epithelium: a light and electron microscopic study. J Pathol 1981; 133: 341-359.

16. Rogers DF, Jeffery PK. Inhibition by oral N-acetylcysteine of cigarette smoke-induced "bronchitis" in the rat. Exp Lung Res 1986; 10: 267-283.

17. Harkema JR, Hotchkiss JA. In vivo effects of endotoxin on intraepithelial mucosubstances in rat pulmonary airways. Quantitative histochemistry. Am J Pathol 1992; 141: 307-317.

18. Li D, Jeffery PK. Experimental induction of goblet cell hyperplasia in vivo. In: Rogers DF, ed. Airway mucus: Basic Mechanisms and Clinical Perspectives. Basle, Birkhauser Verlag, 1997; (in press).

19. Jeffery PK. Structure and function of adult tracheobronchial epithelium. In: McDowell EM, ed. Lung Carcinomas. London, Churchill Livingstone, 1987; pp. 42-73.

20. Ayers M, Jeffery PK. Proliferation and differentiation in adult mammalian airway epithelium: a review. Eur Respir J 1988; 1: 58-80.

21. Boat TF, Cheng PW, Iyer RN, Carlson DM, Polony I. Human respiratory tract secretions: mucous glycoproteins of nonpurulent tracheobronchial secretions, and sputum of patients with bronchitis and cystic fibrosis. Arch Biochem Biophys 1976; 177: 95-104.

22. Roomans GM, von Euler AM, Muller RM, Gilljam H. $\mathrm{X}$-ray microanalysis of goblet cells in bronchial epithelium of patients with cystic fibrosis. J Submicrosc Cytol 1986; 18: 613-615.

23. Jeffery PK, Reid L. The ultrastructure of the airway lining and its development. In: Hodson WA, ed. The 
Development of the Lung. New York, Marcel Dekker Inc., 1977; pp. 87-134.

24. Rogers AV, Dewar A, Corrin B, Jeffery PK. Identification of serous-like cells in the surface epithelium of human bronchioles. Eur Respir J 1993; 6: 498-504.

25. Spicer SS, Mochizuki I, Setser ME, et al. Complex carbohydrates of rat tracheobronchial surface epithelium visualized ultrastructurally. Am J Anat 1980; 158: 93-103.

26. Plopper CG. Comparative morphologic features of bronchiolar epithelial cells. Am Rev Respir Dis 1983; 128: S37-S41.

27. Gil J, Weibel E. Extracellular lining of bronchioles after perfusion-fixation of rat lungs for electron microscopy. Anat Rec 1971; 169: 185-200.

28. de Water R, Willems LNA, van Muijens GNP, et al. Ultrastructural localization of bronchial antileukoprotease in central and peripheral human airways by a gold-labelling technique using monoclonal antibodies. Am Rev Respir Dis 1986; 133: 882-890.

29. Willems LNA, Kramps JA, Jeffery PK, Dijkman JH Antileukoprotease in the developing foetal lung. Thorax 1988; 43: 784-786.

30. Van Scott MR, Hester S, Boucher RC. Ion transport by rabbit nonciliated bronchiolar epithelial cells (Clara cells) in culture. Proc Natl Acad Sci USA 1987; 84: 5496-5500.

31. Sorokin SP, Hoyt RF, Pearsall AD. Comparative biology of small granule cells and neuroepithelial bodies in the respiratory system: short review. Am Rev Respir Dis 1983; 128: S26-S31.

32. Lauweryns JM, Van Lommel A. The intrapulmonary neuroepithelial bodies after vagotomy: demonstration of their sensory neuroreceptor-like innervation. Experientia 1983; 39: 1123-1124.

33. Lauweryns JM, van Ranst L, Verhofstad AAJ. Ultrastructural localization of serotonin in the intrapulmonary neuro-epithelial bodies of neonatal rabbits by use of immuno-electron microscopy. Cell Tissue Res 1986; 243: 455-459.

34. Wharton J, Polak JM, Bloom SR, et al. Bombesin-like immunoreactivity in the lung. Nature 1978; 273: 769-770.

35. McDowell EM, Trump BF. Conceptual review: histogenesis of preneoplastic and neoplastic lesions in tracheo-bronchial epithelium. Sur Synth Pathol Res 1983; 2: 235-279.

36. Keenan KD. Cell injury and repair of the tracheobronchial epithelium. In: McDowell EM, ed. Lung Carcinomas. London, Churchill-Livingstone, 1987; pp. 74-93.

37. Jeffery PK. The structure and function of the mucussecreting cells of cat and goose airway epithelium. In Porter R, ed. Respiratory Tract Mucus. 56th CIBA Foundation Symposium. Oxford, Elsevier/Excerpta Medica, 1978; pp. 5-24.

38. Gashi AA, Nadel JA, Basbaum CB. Autoradiographic studies of the distribution of ${ }^{35}$ sulfate label in ferret trachea: effects of stimulation. Exp Lung Res 1987; 12: 83-96.

39. Meyer C, Christner A, Linss W, Quade R, Geyer G. Ultrahistochemical demonstration of the glycocalyx on the surface of tracheal epithelium by means of the colloidal iron method. Acta Histochem 1971; 39: 176-178.

40. Spicer SS, Schulte BA, Thomopoulos GN. Histochemical properties of the respiratory tract epithelium in different species. Am Rev Respir Dis 1983; 128: S20-S26.

41. Tos M. Development of the tracheal glands in man. Acta Pathol Microbiol Scand 1966; 185: 1-130.

42. Meyrick B, Sturgess J, Reid L. Reconstruction of the duct system and secretory tubules of the human bronchial submucosal gland. Thorax 1969; 24: 729-736.
43. Nathanson I, Nadel JA. Review: movement of electrolytes and fluid across airways. Lung 1984; 162: 125-137.

44. Phipps RJ, Williams IP, Richardson PS, Pell J, Pack RJ, Wright N. Sympathomimetic drugs stimulate the output of secretory glycoproteins from human bronchi in vitro. Clin Sci 1982; 63: 23-28.

45. Douglas AN. Quantitative study of bronchial mucous gland enlargement. Thorax 1980; 35: 198-201.

46. Lamb D, Reid L. Histochemical types of acidic glycoprotein produced by mucous cells of the tracheobronchial glands in man. J Pathol 1969; 98: 213-229.

47. Lamb D, Reid L. Histochemical and autoradiographic investigation of the serous cells of the human bronchial glands. J Pathol 1970; 100: 127-138.

48. Jones R, Bolduc P, Reid L. Goblet cell glycoprotein and tracheal gland hypertrophy in rat airways: the effect of tobacco smoke with or without the anti-inflammatory agent phenylmethyloxadiazole. Br J Exp Pathol 1973; 54: 229-239.

49. Spicer SS, Schulte BA, Chakrin LW. Ultrastructural and histochemical observations of respiratory epithelium and gland. Lung Res 1983; 4: 137-156.

50. Marson C, Cava C, Longnon J, Roujeau J. Cytochemical and histochemical characterization of epithelial mucins in human bronchi. Acta Cytologica 1978; 22: 562-565.

51. Cheng Pi-Wan, Boat TF, Cranfill K, Yankaskas JR, Boucher RC. Increased sulfation of glycoconjugates by cultured nasal epithelial cells from patients with cystic fibrosis. J Clin Invest 1989; 84: 68-72.

52. Bowes D, Corrin B. Ultrastructural immunocytochemical localization of lysozyme in human bronchial glands. Thorax 1977; 32: 163-170.

53. Bowes D, Clark AE, Corrin B. Ultrastructural localisation of lactoferrin and glycoprotein in human bronchial glands. Thorax 1981; 36: 108-115.

54. Brandtzaeg P. Mucosal and glandular distribution of immunoglobulin components: immunohistochemistry with a cold ethanol-fixation technique. Immunol 1974; 26: 1101-1113.

55. Kramps JA, Franken C, Meijer CJLM, Dijkman JH. Localization of low-molecular weight protease inhibitor in serous secretory cells of the respiratory tract. $J$ Histochem Cytochem 1981; 29: 712-719.

56. Lamb D. Mucus secretion in hypersecretory states. Bronchus 1968; 18: 453-465.

57. Lopez-Vidriero MT, Reid L. Bronchial mucus in health and disease. Br Med Bull 1978; 34: 63-88.

58. Kollestrom N, Lord PW, Whimster WF. A difference in the composition of bronchial mucus between smokers and nonsmokers. Thorax 1977; 32: 155-159.

59. Jany B, Gallup M, Tsuda T, Basbaum C. Mucin gene expression in rat airways following infection and irritation. Biochem Biophys Res Commun 1991; 181: 1-8.

60. Audie JP, Janin A, Porchet N, Copin MC, Gosselin B, Aubert JP. Expression of human mucin genes in respiratory, digestive, and reproductive tracts ascertained by in situ hybridization. J Histochem Cytochem 1993; 41: 1479-1485.

61. Chambers JA, Hollingsworth MA, Trezise AEO, Harris A. Developmental expression of mucin genes, $M U C 1$ and MUC2. J Cell Sci 1994; 107: 413-424.

62. Dohrman A, Tsuda T, Escudier E, et al. Distribution of lysozyme and mucin (MUC2 and MUC3) mRNA in human bronchus. Exp Lung Res 1994; 20: 367-380.

63. Li D, Wang D, Majumdar S, et al. Localization and up-regulation of mucin (MUC2) gene expression in human nasal biopsies of patients with cystic fibrosis. $J$ Pathol 1997; 181: 305-310. 